\title{
EMOSI POSITIF: DALAM HUBUNGAN STORE ATMOSPHERE TERHADAP IMPULSE BUYING
}

\section{Intan Kusuma Wardani}

Fakultas Ekonomi dan Bisnis

Universitas Sains Al-Qur'an (UNSIQ) Jawa Tengah di Wonosobo

intankusumaw257@gmail.com

\section{Trihudiyatmanto}

Fakultas Ekonomi dan Bisnis

Universitas Sains Al-Qur'an (UNSIQ) Jawa Tengah di Wonosobo

trihudiyatmanto@unsiq.ac.id

\begin{abstract}
This study aims to identify the influence of store atmosphere on impulse buying through positive emotions in Pamong Siswo minimarket consumers in Wonosobo. This research is a quantitative research using accidental sampling method. The population in this study were consumers of the Pamong Siswo minimarket in Wonosobo. The sampling technique used non-probability sampling with a total sample of 105 people. The data collection technique uses offline and online questionnaires that have been tested for validity and reliability. The data analysis technique used to answer the hypothesis is Structural Equation Modeling (SEM) with AMOS software. The results of this study indicate that: (1) Store Atmosphere has a positive and significant effect on Positive Emotions, (2) Store Atmosphere has a positive and significant effect on Impulse Buying, (3) Positive Emotions have a positive and significant impact on Impulse Buying, (4) Store Atmosphere positive and significant effect on Impulse Buying through Positive Emotions. This is evidenced by the positive emotion mediating coefficient of 0.459 , which is greater than the direct effect of 0.366 , so that the positive emotion variable is proven to be able to mediate the influence of the Store Atmosphere on Impulse Buying.
\end{abstract}

Keywords: store atmosphere, emosi positif, dan impulse buying.

Corresponding author:

Email Address : trihudiyatmanto@unsiq.ac.id(Wonosobo, Jawa Tengah)

Received 13 Agustus 2021, Accepted 16 Agustus 2021, Published Agustus 2021

\section{PENDAHULUAN}

Perkambangan zaman dan bertumbuhan perekonomian yang semakin berkembang tanpa disadari juga ikut berdampak pada perubahan gaya berbelanja masyarakat Indonesia. Dahulu masyarakat Indonesia lebih suka berbelanja di pasar tradisional. Namun, kini mereka cenderung lebih suka berbelanja di pasar modern. Mulai dari swalayan, departement store, hypermart, hingga minimarket. Perubahan perilaku konsumen inilah yang ikut menjadi salah satu faktor bekembangnya bisnis retail di Indonesia.

Ritel modern mampu memberikan banyak tawaran yang cukup menarik. Mulai dari suasana toko yang nyaman, kegiatan promosi dan display produk yang menarik, sehingga mampu menciptakan emosi positif pada diri konsumen untuk melakukan pembelian secara spontan. Industri ritel modern merupakan industri yang strategis dan memberikan kontribusi terhadap peningkatan perekonomian Indonesia.

Minimarket merupakan salah satu bentuk usaha yang mengalami pertumbuhan cukup pesat. Kini sudah ada banyak sekali minimarket bermunculan dengan menawarkan fasilitas yang semakin lengkap. Pada dasarnya keberhasilan usaha ritel terletak pada ketersediaan produk sehari - hari, baik secara kuantitas maupun kualitas. Terlebih lagi pada produk dengan harga terjangkau yang mampu 
IntanK.W. \&M.Trihudiyatmanto/Emosi Positif........

menjaring masyarakat berpenghasilan menengah ke bawah.

Perilaku pembelian tidak terencana (impulse buying) tersebut dipengaruhi oleh store atmosphere sebuah toko sehingga dapat meninmbulkan positive emotion yang dapat juga meningkatkan konsumen dalam melakukan impulse buying (Devi DAC, dkl 2020). Store atmosphere yang baik, akan tercipta emosi positif dalam diri konsumen yang dapat mendorong konsumen untuk melakukan pembelian impulsive (Rahayu, RD, 2019). Store atmosphere menggambarkan moment of truth, yaitu situasi langsung yang dirasakan konsumen saat berbelanja. Jika setting dari suasana tersebut optimal, maka perusahaan retail akan mampu menyentuh emosi konsumen (Rahayu, RD, 2019).

Pada penelitian yang dilakukan (Angga, D dkk, 2018) membuktikan jika terdapat pengaruh yang positif dan signifikan antara store atmosphere terhadap impulse buying. Penelitian yang dilakukan (Devi, DAC. dkk, 2020) membuktikan jika store atmosphere berpengaruh positif dan signifikan terhadap impulse buying. Penelitian yang dilakukan (Rahayu, RD dkk, 2019) juga membuktikan jika store atmosphere berpengaruh positif terhadap pembelian impulsive dengan emosi positif. Berdasarkan beberapa penelitian yang menyatakan bahwa store atmosphere berpengaruh secara positif dan signifikan.

Namun, penelitian yang dilakukan (Artana, IPW dkk, 2019) membuktikan jika store atmosphere tidak mempunyai pengaruh yang signifikan terhadap impulse buying. Penelitian yang dilakukan (Trihudiyatmanto, M. 2020) membuktikan jika store atmosphere tidak berpengaruh positif signifikan impulse buying. Dengan adanya hasil penelitian yang berbeda tersebut, maka peneliti menawarkan konsep mediasi, yaitu emosi positif. Alasan pemberian variabel mediasi emosi positif mengacu pada penelitian yang dilakukan oleh (Davota Ikanubun, S. M, 2019) dengan Judul (Pengaruh Hedonic Shopping terhadap Impulse Buying yang Dimediasi Emosi Positif (Survei Pada Konsmen Toko Fashion di Kota " $X ")$.

Berdasarkan latar belakang yang sudah dipaparkan sebelumnya, maka rumusan masalah penelitianini adalah sebagai berikut:

1. Apakah store atmosphere berpengaruh terhadap emosi positif pada konsumen minimarket Pamong Siwso?
2. Apakah store atmosphere berpengaruh terhadap impulse buying pada konsumen minimarket Pamong Siwso?

3. Apakah emosi positif berpengaruh terhadap impulse buying pada konsumen minimarket Pamong Siwso?

4. Apakah store atmosphere berpengaruh terhadap impulse buying pada konsumen minimarket Pamong Siwso dengan emosi positif sebagai variabel intervening?

\section{TINJAUAN PUSTAKA \\ Impulse Buying}

Menurut Rook dan Fisher (1995) pembelian impulsif diartikan sebagai kecenderungan konsumen untuk membeli secara spontan, refleks, tiba - tiba, dan otomatis (Doddy Angga A, 2018). Beatty and Ferrel (1998), pembelian impulsive adalah terjadi tiba tiba dan pembelian dengan segera tanpa niat sebelum belanja untuk membeli produk secara spesifik atau untuk memenuhi tugas pembelian secara spesifik. Utami (2017) pembelian impulsif disebabkan oleh stimulus di tempat belanja untuk mengingatkan konsumen akan apa yang harus dibeli atau karena pengaruh display, promosi, dan usaha - usaha pemilik tempat belanja untuk menciptakan kebutuhan baru dalam (Rahayu. RD dkk, 2019). Kancen dan Lee (2002) impulse buying adalah sebuah tindakan pembelian produk yang tidak direncanakan sebelumnya yang terjadi sebagai dari akibat rangsangan yang diterima dan tindakan ini langsung diputuskan saat itu juga.

\section{Store Atmosphere}

Storeo Atmosphere merupakan salah satu elemen penting dari retailing mix yang mampu mempengaruhi proses keputusan pembelian konsumen, karena dalam proses keputusan pembelian konsumen tidak hanya memberi respon terhadap barang dan jasa yang ditawarkan oleh ritel (Doddy Angga dkk, 2018). Utami (2017), store atmosphere adalah rancangan respon emosional dan perseptual pelanggan yang pada akhirnya mempengaruhi pelanggan dalam membeli barang (Rahayu, RD dkk, 2019)

\section{Emosi Positif}

Menurut Leba (2015) emosi positif adalah suasanaohati seseorang (bahagia, senang, dan gembira) yang dirasakan seseorang, sehingga mempengaruhi pengambilan secara spontan 
terhadap suatu produk (Devi. DAC dkk, 2020). Konsumen dengan emosi positif menunjukkan dorongan yang lebih besar dalam melakukan pembelian karena memiliki perasaan yang tidak dibatasi oleh keadaan lingkungan sekitarnya dan merasa lebih dihargai jika memiliki suatu barang yang dibeli tersebut (Devi. DAC dkk, 2020).

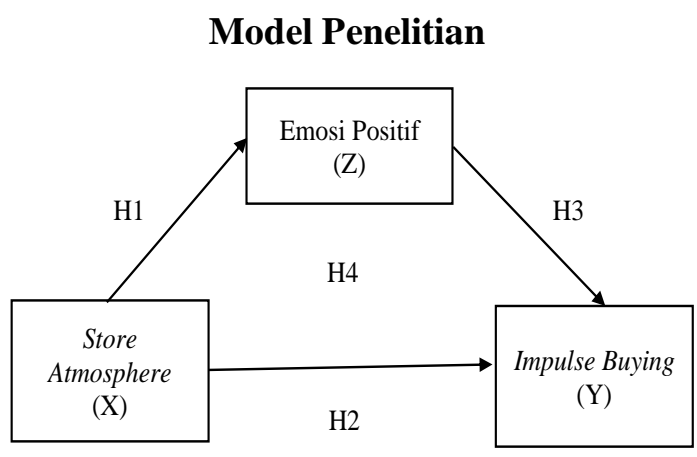

Gambar 1. Model Penelitan

\section{METODE PENELITIAN \\ Jenis Penelitian}

Jenis penelitian yangodigunakan dalam penelitian ini adalah penelitianokuantitatif. Metode yang digunakan, melalui survei yaitu suatu metode pengumpulan data dengan menggunakan kuesioner untuk mendapatkan tanggapan dari responden yang menjadi sampel. Penelitian ini merupakan penelitian kuantitatif, di mana peneliti berusaha untuk menemukan pengaruh langsung dan tidak langsungodari variabel bebas, yaitu store atomosphere terhadap impulse buying dengan variabel mediasi berupa emosi positif.

\section{Populasi dan Teknik Pengambilan Sampel}

Populasi adalahowilayah generalisasi dan terdiri dari objek atau subjekopenelitian yang mempunyai kuantitasodan karakteristik tertentu yangoditetapkan oleh penelitiountuk dipelajari dan kemudianoditarik kesimpulannya (Sugiyono, 2011). Populasiodalam penelitian ini adalah konsumen yang pernahomelakukan pembeliandi minimarket di Pamong Siswo Sambek, Kota Wonosobo yang akan diambil sampel sebanyak 105 orang.

Pengambilan sampel penelitian ini menggunakan beberapa pertimbangan tertentu. menurut (Hair, 2010) bahwa apabila ukuran sampel terlalu besar, misalnya: 400, maka metode menjadi sangat sensitive, sehingga sulit untuk mendapatkan ukuran- ukuran goodness-of fit yang baik, sehingga disarankan bahwa ukuran sampel minimun adalah lima sampai sepuluh observasi untuk setiap parameter yang diestimasi.

Pada penelitian ini terdapat 15 indikator dikali 7. Berarti jumlah sampel yang diambil sebesar 105 sampel atau responden. Adapun pengambilan data dilakukan dengan teknik non probability sampling, yaitu tidakomemberikan peluangoatau kesempatan yang sama bagiosetiap unsur atau anggota populasi untuk dipilih menjadi sampel, sedangkan metode, di mana peneliti tidak mempunyai pertimbangan lain, kecuali berdasarkan kemudahan saja.

\section{Teknik Analisis Data}

Penelitian membutuhkanoteknik analisis data dan interprestasi yang akan digunakan untuk menjawab pertanyaan pertanyaan penelitian untuk mengungkapkan fenomena tertentu, sehingga analisis data adalah proses penyederhanaan data ke dalam bentuk yang lebih mudah dibaca dan diinterprestasikan. Model yangakan digunaan dalam penelitian ini adalah model kausalitas atau hubungan atau pengaruh dan untuk menguji hipotesis yang diajukan, maka teknik analisis data yang digunakan adalah Structural Equationo Models (SEM).

Penggunaan metode analisis SEM dikarenakan dapat mengidentifikasi dimensi dimensi dari sebuahokonstruk danopada saat yang sama mampu mengukur pengaruh atau derajat hubungan antar faktor yang telah diidentifikasi dimensinya (Ferdinand, 2010). Ferdinand (2014) sebuah permodelan SEM yang lengkap pada dasarnya terdiri dari Measurement Models atau indikator empirisnya. Structural Models adalah model mengenai struktur hubungan yang membentuk atau menjelaskan kualitas antar faktor. Dalam membuat permodelan SEM yang lengkap perlu dilakukan langkah - langkah, berikut ini:

1. Pengembangan model teoritis

2. Pengembangan diagram alur (path diagram)

3. Konversi diagram alur ke dalam persamaan

a. Persamaan - persamaan struktural (structural equations)

b. Pada tahap ini ditentukan variabel mana mengukur konstruk mana, serta membentuk serangkaian matriks yang menunjukkan korelasi yang dihipotesiskan antar konstruk atau variabel. 
4. Memilih matriks input dan estimasi model

5. Kemungkinan munculnya masalah identifikasi

6. Evaluasi kriteria Goodness of fit asumsi - asumsi SEM:

Pertama yang dilakukan adalah bahwa data yang digunakan harus memenuhi asumsi- asumsi sem, yaitu:

1) Ukuran sampel

2) Normalitas dan linearitas

3) Outliers

4) Multicollinearity dan singularity

Setelah asumsi - asunsi SEModilihat, hal berikutnya adalah melakukan kriteria yang akan kita gunakan untuk mengevaluasi model dan pengaruh pengaruh yang ditampilkan dalam model, yaitu Uji Kesesuaian dan Uji Statistik, meliputi:
a) X2 - Chi Square Statistik
b) RMSEA (The Root Mean Square Error of Approximation)
c) GFI (Goodness of Fit Indeks)
d) AGFI (Ajusted Goodness of Fit Indeks)
e) $\mathrm{CMIN} / \mathrm{DF}$
f) TLI (Tucker Lewis Indeks)
g) CFI (Comparative Fit Indeks)

7. Interprestasi dan Modifikasi Model

\section{HASIL DAN PEMBAHASAN Uji Validitas Uji Reliabilitas}

Berikut iniomerupakan hasil uji validitas dari konsumen minimarket Pamong Siswo di Wonosobo. Berikut ini merupakan hasil pengolahan data kuesioner konsumen minimarket Pamong Siswo:

Tabel 1

Hasil Uji Validitas Data

\begin{tabular}{|c|c|c|c|}
\hline Variabel & Kisaran Korelasi & Sig & Ket \\
\hline SA & $0,666^{* *}-0,814^{* *}$ & 0,000 & Valid \\
\hline EP & $0,743^{* *}-0,833^{* *}$ & 0,000 & Valid \\
\hline IB & $0,711^{*}-0,800^{* *}$ & 0,000 & Valid \\
\hline
\end{tabular}

Sumber: Data primer yang diolah, (2021)

Menurut (Ghozali, 2006) uji validitas dilakukan dengan menghitung korelasi bivariate antar setiap skor indikator dengan skor total. Suatu indikator dinyatakan valid, apabila korelasi antar indikator menunjukkan hasil yang signifikan pada tingkat 0,00 dan 0,05. Menurut data Tabel 1. di atas, maka dapat disimpulkan jika semua indikator dari uji validitas dinyatakan valid, dikarenakan korelasi antar indikator menunjukkan hasil yangosignifikan, yaitu kurang dari 0,05 .

Uji reliabilitas dilakukan pada item yang dianggap valid. Reliabilitas adalah suatu indeks yangomenunjukkan sejauh mana alat ukur dapat mengukur jika dilakukan oleh orang yang sama dalam waktu yang berbeda, maka alat ukur tersebut reliabel. Suatu konstruk dinyatakan reliabel jika memberikan nilai Cronbach Alpha $>0,07$. Hasil pengolahan data dalam penelitian ini sebagai berikut:

\section{Tabel 2.}

Hasil Uji Reliabilitas

\begin{tabular}{|c|c|c|c|}
\hline Variabel & $\begin{array}{c}\text { Cronbach } \\
\text { Alpha }\end{array}$ & Batas & Ket \\
\hline SA & 0,859 & 0,7 & Reliable \\
\hline EP & 0,780 & 0,7 & Reliable \\
\hline IB & 0,744 & 0,7 & Reliable \\
\hline
\end{tabular}

Sumber: Data primer yang diolah, (2021)

Menurut (Ghozali, 2006) tingkat reliabilitas suatu konstruk dapat dilihat dari hasil uji statistik Cronbach Alpha. Berdasarkan data tabel di atas berdasarkan keterangan (Ghozali, 2007) yang menjelaskan jika indikator dan variabel dikatakan reliabel apabila nilai Cronbach Alpha > 0,07. Berdasarkan keterangan tersebut dapat disimpulkan bahwa seluruh variabel reliabel.

\section{Proses Analisis Data}

Dalam penelitian ini teknik analisis data yang digunakan adalah Sturctural Equation Modeling (SEM) dengan software AMOS, karena jumlah data yang digunakan dalam penelitian ini sebanyak 105 responden, dengan langkah - langkah sebagai berikut:

\section{Pengembangan Model Berbasis Teori}

Langkah pertama dalam pengembangan model SEM adalah pengembangan atau pencarian model yang mempunyai justifikasi teoristis yang kuat. Seorang peneliti harus melakukan serangkaian telaah pustaka yang intens guna mendapatkan justifikasi atas model teoristis yang dikembangkan. Variabel dan indikator tersebut disajikan dalam bentuk Tabel 3.

\section{Pengembangan Diagram Alur}

Pengembangan diagram akan mempermudah 
Tabel 3.

Variabel dan Indikator

\begin{tabular}{|c|l|c|}
\hline Variabel & \multicolumn{1}{|c|}{ Indikator } & Kode \\
\hline \multirow{4}{*}{$\begin{array}{c}\text { Store } \\
\text { Atmosphere } \\
(X)\end{array}$} & Desain toko & SA1 \\
\cline { 2 - 3 } & Tata letak toko & SA2 \\
\cline { 2 - 3 } & Komunikasi visual & SA3 \\
\cline { 2 - 3 } & Penerangan & SA4 \\
\cline { 2 - 3 } & Warna & SA5 \\
\cline { 2 - 3 } & Musik & SA6 \\
\cline { 2 - 3 }$(Z)$ & Aroma & SA7 \\
\hline \multirow{4}{*}{\begin{tabular}{l} 
Emosi Positif \\
\cline { 2 - 3 }
\end{tabular}} & Senang & EP2 \\
\cline { 2 - 3 } & Puas & EP3 \\
\cline { 2 - 3 } & Syaman & EP4 \\
\hline \multirow{4}{*}{$\begin{array}{l}\text { Impulse } \\
\text { Buying (Y) }\end{array}$} & $\begin{array}{l}\text { Semangat } \\
\text { intensitas }\end{array}$ & IB2 \\
\cline { 2 - 3 } & kegairahan dan stimulus & IB3 \\
\cline { 2 - 3 } & $\begin{array}{l}\text { Ketidak pedulian akan } \\
\text { akibat }\end{array}$ & IB4 \\
\hline
\end{tabular}

Sumber: Pengolahan data, (2021)

peneliti dalam melihat hubungan - hubungan kauasalitas yang ingin diuji. Peneliti biasanya bekerja dengan "construk" atau "factor", yaitu konsep - konsep yang memiliki pijakan teoritis yangocukup untuk menjelaskan berbagai hubungan. Konstruk - konstruk yang dibangun dalam dalam diagram alur dapat dibagiomenjadi dua kelompok, yaitu: konstruk endogen dan konstruk eksogen. Konstruk eksogen dikenal sebagaio"source variables" oatau "independent variables" yang diprediksi oleh variabel yang lain dalam model. Konstruk endogen adalah faktor - faktor yang diprediksi oleh satu atau beberapa konstruk endogen lainnya, tetapi konstruk eksogen hanya dapat berhubungan kasual dengan konstruk endogen.

Menurut Gambar 2. di atas, ringkasan structural equation modeling tersebut

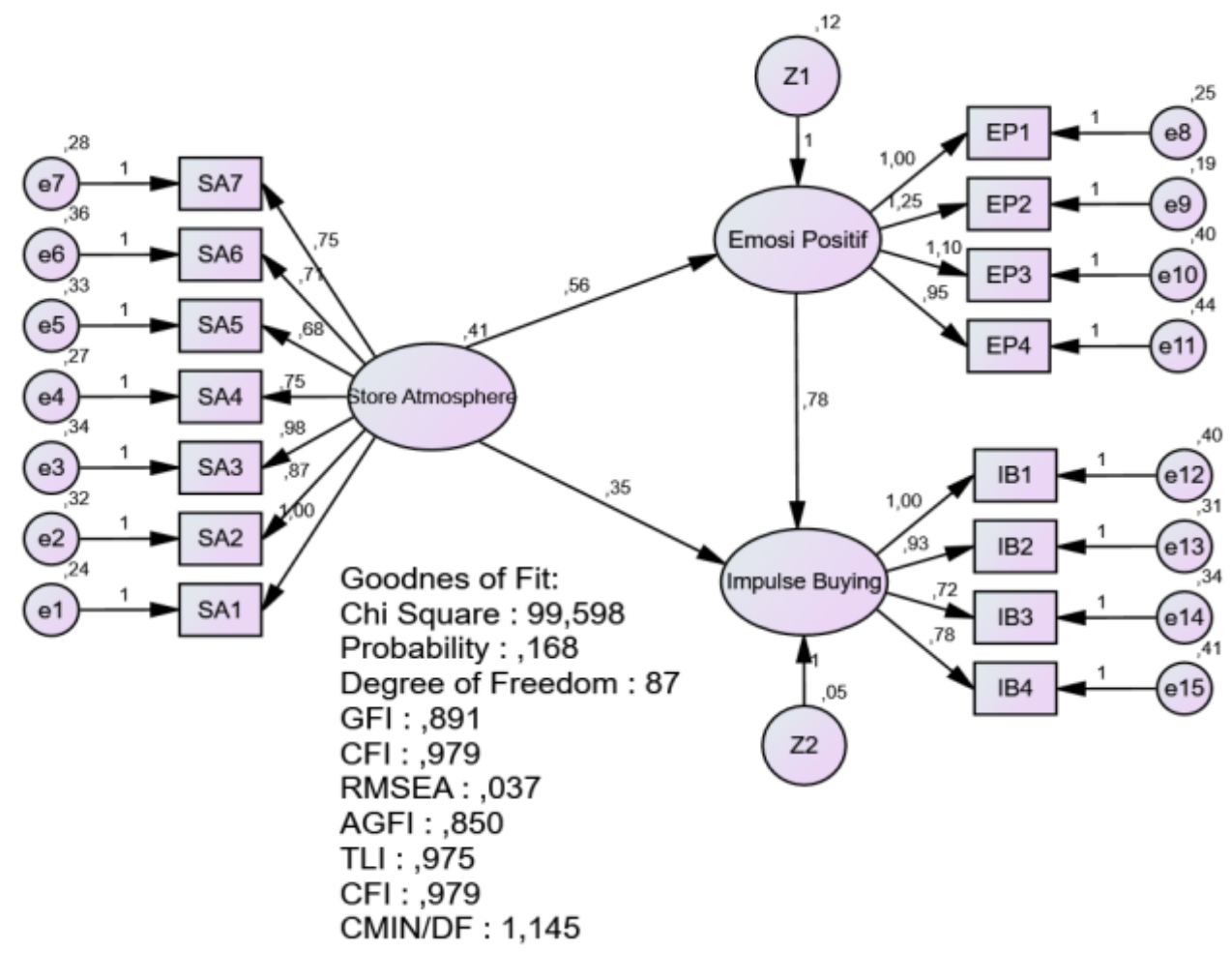

Sumber: Data primer yang diolah, (2021)

Gambar 2.

Analisis Structural Equation Modeling

dapat dilihat dalam Tabel 4.

Tampak bahwa uji yangoada telah memenuhi syarat yang ditentukan atau mendekati dengan nilai yang disarankan adalah GFI / AGFI $\geqslant 0,90 / \geqslant 0,90$ dan masuk kategori marjinal. Dengan demikian, dinyatakan 
bahwa model telah dinyatakan fit untuk dianalisis (Wijanto, 2008).

Tabel 4.

Goodness of Fit Confirmatory Factor Analysis

\begin{tabular}{|l|c|c|c|}
\hline $\begin{array}{c}\text { Goodness of Fit } \\
\text { Indeks }\end{array}$ & $\begin{array}{c}\text { Cut-off } \\
\text { Value }\end{array}$ & $\begin{array}{c}\text { Hasil } \\
\text { Analisis }\end{array}$ & $\begin{array}{c}\text { Evaluasi } \\
\text { Model }\end{array}$ \\
\hline Chi-Square & $\leq 107,5217$ & 99,598 & GoodFit \\
\hline Probability & $\geq 0,05$ & 0,168 & GoodFit \\
\hline RMSEA & $\leq 0,08$ & 0,037 & GoodFit \\
\hline GFI & $\geq 0,90$ & 0,891 & Marginal \\
\hline AGFI & $\geq 0,90$ & 0,859 & Marginal \\
\hline CMIN/Df & $\leq 2,00$ & 1,145 & GoodFit \\
\hline TLI & $\geq 0,95$ & 0,975 & GoodFit \\
\hline CFI & $\geq 0,95$ & 0,979 & GoodFit \\
\hline
\end{tabular}

Sumber: Data primer yang diolah, (2021)

\section{Pengujian Asumsi SEM Normalitas Data}

Berdasarkan data dianalisis untuk melihat apakah asumsi normalitas data terpenuhi atau tidak hingga dapat diolah lebih lanjut dalam permodelan SEM. Sebaran data SEM dianalisis terlebih dahulu. Distribusi data dikatakan normal pada tingkat signifikansi 0,05 jika critical ratioo(CR) skewness (kemiringan) atau CR curtosis (keruncingan) tidak lebih dari 2,58 (Santosa, 2011). Berdasarkan tabel dia atas dapat dilihat bahwa bahwa nilai c.r untuk multivariate adalah 2,285 yang berada $\pm 2,58$, sehingga dapat disimpulkan bahwa data berdistribusi normal secara multivariate.

\section{Multivariate Outliers}

Evaluasi terhadap multivariate outliers perlu dilakukan, karena walaupun ada data yang

Tabel 5.

Hasil Uii Normalitas

\begin{tabular}{|l|r|r|r|r|r|r|}
\hline Variable & $\min$ & $\max$ & skew & c.r. & kurtosis & c.r. \\
\hline IB4 & 2,000 & 5,000 &,- 424 & $-1,772$ &,- 494 & $-1,033$ \\
IB3 & 2,000 & 5,000 &,- 390 & $-1,632$ &,- 557 & $-1,166$ \\
IB2 & 2,000 & 5,000 &,- 533 & $-2,231$ &,- 329 &,- 688 \\
IB1 & 2,000 & 5,000 &,- 601 & $-2,513$ &,- 424 &,- 887 \\
EP4 & 2,000 & 5,000 &,- 525 & $-2,196$ &,- 214 &,- 448 \\
EP3 & 2,000 & 5,000 &,- 314 & $-1,312$ &,- 838 & $-1,753$ \\
EP2 & 2,000 & 5,000 &,- 265 & $-1,107$ &,- 550 & $-1,150$ \\
EP1 & 2,000 & 5,000 &,- 285 & $-1,192$ &,- 448 &,- 938 \\
SA7 & 2,000 & 5,000 &,- 523 & $-2,187$ &, 353 &, 739 \\
SA6 & 2,000 & 5,000 &,- 428 & $-1,791$ &,- 350 &,- 732 \\
SA5 & 2,000 & 5,000 &,- 711 & $-2,974$ &, 848 & 1,774 \\
SA4 & 2,000 & 5,000 &,- 580 & $-2,425$ &, 551 & 1,153 \\
SA3 & 2,000 & 5,000 &,- 896 & $-3,748$ &, 157 &, 329 \\
SA2 & 2,000 & 5,000 &,- 835 & $-3,493$ &, 064 &, 134 \\
SA1 & 2,000 & 5,000 &,- 593 & $-2,480$ &,- 177 &,- 370 \\
Multivariate & & & & & 10,070 & 2,285 \\
\hline
\end{tabular}

Sumber: Data primer yang diolah, (2021)

dianalisis menunjukkan tidak adanya outliers. Evaluasi terhadap multivariate outliers perlu dilakukan, karena walaupun ada data yang dianalisis menunjukkan tidak adanya outliers pada tingkat univariate, tetapi observasi observasi itu dapat menjadi outliers bila sudah dikombinasikan. Jarak Mahalanobis untuk tiap tiap observasi dapat dihitung dan akan menunjukkan jarak sebuah observasi dari rata rata semua variabel dalam sebuah ruangan multi dimensional. Berdasarkan hasil output di atas, maka dapat dilihat bahwa tidak ada data yang ekstrem, sehingga tidak ada yang outliers dan dapat dilakukan ke tahap selanjutnya.

Evaluasi Multicolleniarity dan Singularity 
IntanK.W. \&M.Trihudiyatmanto/Emosi Positif........

Pengujian data selanjutnya adalah untuk melihat apakah terdapat multikoleniaritasdan singularitas dapat diketahui dari nilai tolerance lebih dari 0,1 nilai VIF kurang dari 10 . Berikutnya adalah Tabel 7. merupakan hasil multicolleniarity dan singularity.

Tabel 6.

Data Unvariate Outliers

\begin{tabular}{|l|r|r|r|r|r|}
\hline & $\mathrm{N}$ & Minimum & Maximum & Mean & Std. Deviation \\
\hline Zscore(SA1) & 105 & -2.57507 & 1.12880 & .0000000 & 1.00000000 \\
\hline Zscore(SA2) & 105 & -2.83215 & .93210 & .0000000 & 1.00000000 \\
\hline Zscore(SA3) & 105 & -2.52545 & .94842 & .0000000 & 1.00000000 \\
\hline Zscore(SA4) & 105 & -2.90783 & 1.31322 & .0000000 & 1.00000000 \\
\hline Zscore(SA5) & 105 & -2.85401 & 1.28891 & .0000000 & 1.00000000 \\
\hline Zscore(SA6) & 105 & -2.78067 & 1.20074 & .0000000 & 1.00000000 \\
\hline Zscore(SA7) & 105 & -2.83242 & 1.33680 & .0000000 & 1.00000000 \\
\hline Zscore(EP1) & 105 & -2.94318 & 1.29016 & .0000000 & 1.00000000 \\
\hline Zscore(EP2) & 105 & -2.63312 & 1.31656 & .0000000 & 1.00000000 \\
\hline Zscore(EP3) & 105 & -2.39870 & 1.18230 & .0000000 & 1.00000000 \\
\hline Zscore(EP4) & 105 & -2.43780 & 1.21890 & .0000000 & 1.00000000 \\
\hline Zscore(IB1) & 105 & -2.32361 & 1.08075 & .0000000 & 1.00000000 \\
\hline Zscore(IB2) & 105 & -2.64515 & 1.12508 & .0000000 & 1.00000000 \\
\hline Zscore(IB3) & 105 & -2.94474 & 1.15966 & .0000000 & 1.00000000 \\
\hline Zscore(IB4) & 105 & -2.55565 & 1.18867 & .0000000 & 1.00000000 \\
\hline Valid N (listwise) & 105 & & & & \\
\hline & & & & \\
\hline
\end{tabular}

Sumber: Data diolah, (2021)

Tabel 7.

Tabel Hasil Multikoleniaritas

\begin{tabular}{|c|c|c|c|}
\hline Variabel & Tolerance & VIF & Keterangan \\
\hline Store Atmosphere & 0,658 & 1,519 & $\begin{array}{c}\text { Tidak terjadi } \\
\text { multikoleniaritas }\end{array}$ \\
\hline Emosi Positif & 0,558 & 1,519 & $\begin{array}{c}\text { Tidak terjadi } \\
\text { multikoleniartitas }\end{array}$ \\
\hline
\end{tabular}

Sumber: Data diolah, (2021)

Berdasarkan Tabel 7. di atas dapat dilihat jika semua variabel memiliki nilai tolerance lebih dari 0,1 , sedangkan nilai VIF juga menunjukkan nilai yang sama, yaitu sama variabel memiliki nilai VIF kurang dari 10. , sehingga dapat, disimpulkan jika tidak terjadi multicolleniarity dan singularity.

Tabel 8.

Regression Weight Structural Equations

Model

\begin{tabular}{|l||r|rr|r|}
\hline & Estimate & S.E. & C.R. & P \\
\hline EmosiPositif <--- StoreAtmosphere &, 560 &, 102 & 5,491 & $* * *$ \\
ImpulseBuying <--- StoreAtmosphere &, 349 &, 142 & 2,452 & 014 \\
ImpulseBuying <--- EmosiPositif &, 780 &, 203 & 3,837 & $* * *$ \\
\hline
\end{tabular}

Sumber: Data diolah, (2021)

Adapun pengujian hipotesis store atmosphere terhadap impulse buying melalui 
emosi positif sebagai variabel intervening dapat dilihat dalam Tabel 9. Sementara pada Tabel 9; 10; 11 digunakan untuk melihat apakah variabel emosi positif dapat memediasi variabel store atmosphere terhadap impulse buying, yaitu dengan membandingkan nilai standardizet direct effect $<$ standardizet indirect effect, maka dapat dikatakan bahwa variabel mediasi terbukti memiliki pengaruh tidak langsung dalam hubungan antar keuda variabel (independent dan dependent). Dalam penelitian yang dilakukan oleh Trihudiyatmanto (2019) menyebutkan bahwa pengujian efek mediasi dapat dilakukan dengan membandingkan nilai standardizet direct effect dan standardizet indirect effect, di mana jika efek langsung lebih akan meningkat juga. Besar dari efek tidak langsung maka dinyatakan tidak terjadi peran mediasi.

Tabel 9.

Standardized DirectoEffects (Group number 1 - Default model)

\begin{tabular}{|l|r|r|r|}
\hline & SA & EP & IB \\
\hline EP &, 723 &, 000 &, 000 \\
IB &, 366 &, 635 &, 000 \\
\hline
\end{tabular}

Sumber: Data diolah, (2021)

Tabel 10.

Standardized IndirectoEffects (Group number 1 - Default model)

\begin{tabular}{|l|r|r|r|}
\hline & SA & EP & IB \\
\hline EP &, 000 &, 000 &, 000 \\
IB &, 459 &, 000 &, 000 \\
\hline
\end{tabular}

Sumber: Data diolah, (2021)

Tabel 11.

Standardized TotaloEffects (Group number 1 Default model)

\begin{tabular}{|l|r|r|r|}
\hline & SA & EP & IB \\
\hline EP &, 723 &, 000 &, 000 \\
IB &, 826 &, 635 &, 000 \\
\hline
\end{tabular}

Sumber: Data diolah, (2021)

\section{H1: Store Atmosphere berpengaruh positif terhadap Emosi Positif}

Parameter estimasi untuk pengujian store atmosphere terhadap impulse emosi positif menunjukkan nilai CR sebesar 5,491 dengan probabilitas 0,000 , karena kedua nilai tersebut memenuhi syarat untuk penerimaan $\mathrm{H} 1$, yaitu CR 5,491 lebih besar dari 1,96 dan probabilitas lebih kecil dari 0,05. Dengan demikian, dapat disimpulkan bahwa store atmosphere berpengaruh terhadap emosi positif. Artinya semakin baik storeo atmosphere, maka emosi positif yang dirasakan oleh konsumen akan meningkat juga, maka emosi positif yang dirasakan oleh konsumen akan meningkat juga.

Hasil ini sejalan denganopenelitian sebelumnya yang dilakukan oleh Devi, DAC. dkk, (2020) yang membuktikan jika store atmosphere berpengaruh positif dan signifikan terhadap positive emotion. Temuan penelitian tersebut konsisten dengan penelitian yang dilakukan oleh Rahayu, RD dkk (2019) yang menyatakan jika store atmosphere berpengaruh positif terhadap emosi positif.

\section{H2: Store Atmosphere memiliki pengaruh positif terhadap Impulse Buying}

Parameter estimasi untuk pengujian store atmosphereo terhadap impulse buying menunjukan nilai CR sebesar 2,452 dengan probabilitas 0,014, karena kedua hal ini memenuhi syarat untuk penerimaan $\mathrm{H} 2$ yaitu CR 2,425 lebih besar dari 1,96 dan probabilitas lebih kecil dari 0,05. Dengan demikianodapat disimpulkan bahwa store atmosphere berpengaruh terhadap impulse buying. Artinya semakin baik store atmosphere toko, maka keputusan untuk melakukan impulse buying semakin meningkat.

Penelitian senada dengan penelitian yang dilakukan oleh Angga, DA dkk (2018) yang membuktikan jika store atmosphere berpengaruh positif dan signifikan terhadap impulse buying. Konsisten dengan penelitian yang dilakukan oleh Devi, DAC dkk (2020) membuktikan jika store atmosphere berpengaruh terhadap pembelian impulsif.

\section{H3: Emosi Positif memiliki pengaruh positif terhadap Impulse Buying}

Parameter estimasi untuk pengujian emosi positif terhadap impulse buying menunjukkan nilai CR sebesar 3,837 dengan probabilitas 0,000 , karena kedua hal ini memenuhi syarat untuk penerimaan $\mathrm{H} 1$, yaitu $\mathrm{CR}$ 3,837 lebih besar dari 1,96 dan probabilitas lebih kecil dari 0,05 . Dengan demikian, dapat disimpulkan bahwa emosi positif berpengaruh terhadap impulse buying. Artinya semakin sering konsumen merasakan emosi positif, maka konsumen lebih sering atau meningkat melakukan impulse buying saat berbelanja.

Penelitian ini senada dengan penelitian yang dilakukan sebelumnya oleh Ikanubun, D 
dkk (2019) yang membuktikan jika emosi positif berpengaruh positif dan signifikan terhadap impulse buying. Penelitian ini juga konsisten dengan penelitian yang dilakukan oleh Rahayu, RD dkk (2019) yang membuktikan jika emosi positif berpengaruh positif terhadap pembelian impulsif.

\section{H4: Store Atmosphere memiliki pengaruh positif terhadap Buyingmelalui Emosi Positif}

Tabel 9; 10; 11 di atas dapat diketahuiojika nilai standardized directeffect emosi positif dan impulse buying sebesar 0,366, sedangkan nilai standardized indirect effect emosiopositif dan impulseobuying sebesar 0,459. Dengan demikian, dapat dikatakan bahwa emosi positif memediasi store atmosphere terhadap impulse buying. Pertimbangan store atmosphere dengan suasana hati positif yang dirasakan saat melakukan pembelian dapat mempengaruhi keputusan pembelian yang bersifat tidak direncanakan. Mengingat tujuan belanja adalah untuk memenuhi kebutuhan, maka terkadang konsumen melakukan keputusan pembelian tanpa perencanaan yang menunjukkan perilaku impulse buying. Begitupun dengan pengalaman yang menyenangkan saat berbelanja dapat disebabkan oleh pemenuhan hasrat emosional, untuk menghilangkan emosi positif dalam diri konsumen.

\section{PENUTUP}

\section{Kesimpulan}

Berdasaran penelitian yang sudah dilakukan, kesimpulan yang dipaparkan sebagaioberikut:

1. Variabel store atmosphere berpengaruh positifodan terhadap emosi positif. Oleh karena nilai CR lebih besar dari 1,96 yaitu 5,491 dengan probabilitas lebih kecil dari 0.05 , yaitu 0,000 .

2. Variabel store atmosphere berpengaruh /positif terhadap impulse buying. Oleh karena nilai CR lebih besar dari 1,96 yaitu 2,452 dengan probabilitas lebih kecil dari 0,05 , yaitu 0,014 .

3. Variabel emosi positif berpengaruh positif terhadap impulse buying. Demikian, dikarenakan nilai CR lebih besar dari 1,96 yaitu 3,837 dengan probabilitas lebih kecil dari 0,05 , yaitu 0,000 .

4. Variabel emosi positif memediasi store atmosphere terhadap impulse buying. Demikian, dikarenakan nilai parameter estimate tidak langsung lebih besar dari nilainya dari pada nilai parameter yang Saran

berpengaruh langsung.

Bagi peneliti selanjutnya lebih baik memperluas penelitian, sehingga menghasilkan penelitian yang lebih baik dan akurat, serta penelitian ini dapat dijadikan acuan maupun bahan koreksi untuk penelitian. Selanjutnya, penelitian ini hanya fokus pada satu variabel independen, yaitu store atmosphere serta satu variabel dependent yaitu impulse buying. Penggunaan variabel baru atau penambahan variabel dengan indikator baru perlu dilakukan dengan menggunakan indikator lain dalam penelitian selanjutnya agar dapat menghasilkan gambaran yang lebih luas dan hasil yang lebih akurat.

\section{DAFTAR PUSTAKA}

Beatty, S. E. (1998). Impulse Buying: Modeling Its Precursors. Journal of Retailing, 74(2), 169-191.

Davota Ikanubun, S. M. (2019). Pengaruh Hedonic Shopping Terhadap Impulse Buying yang Dimediasi Emosi Positif (Survei Pada Konsumen Toko Fashion di Kota X). Jurnal Ekonomi, Bisnis, dan Akuntansi (JEBA), Volume 21 Nomor 01.

Dewi, K. \&. (2015). Peran Emosi Positif Dalam Memediasi Store Atmosphere Terhadap Pembelian Impulsif (Studi Pada Konsumen Matahari Department Store Duta Plaza Denpasar). E-Jurnal Manajemen Universitas Udayana, 4(12), 4419-4448.

Dewi, K. \&. (2015). Peran Emosi Positif Dalam Memediasi Store Atmosphere Terhadap Pembelian Impulsif (Studi Pada Konsumen Matahari Department Store Duta Plaza Denpasar). E-Jurnal Manajemen Universitas Udayana, 4(12), 4419-4448.

Doddy Angga. A., e. a. (2018). Pengaruh Store Atmosphere Terhadap Impulse Buying Pada Bisnis Ritel . Fakultas Ekonomi dan Bisnis Universitas Mulawarman, Samarinda, 1-5.

Ferdinand, A. (2014). Manajemen Pemasaran: Sebuah Pendekatan Stratejik. . Program Magister Manajemen Universitas Diponegoro Semarang.

Ghozali, I. (2011). Aplikasi Analisis Multivariate dengan Program IBM SPSS 
19. Edisi Kelima Universitas Diponegoro. Semarang.

Ghozali, I. (2016). Stuctural Equation Modeling, Metode Alternatif dengan Partial Least (PLS), Edisi 4. Semarang: Badan Penerbit Universitas Diponegoro.

Hair, J. (1995). Multivariate Data Analysis With Reading . New Jersey: Fourth Edition, Prentice Hall.

Hendri, M. (2006). Pemasaran Ritel. Jakarta: Gramedia Pustaka Utama.

I Putu Widya Artana., e. a. (2019). 6. I Putu Widya Artana, I Gusti Bagus Satria Wisesa, I Komang Setiawan, Ni Luh Putu Mita PramesPengaruh Store Atmosphere, Display Product, Dan Price Discount Terhadap Impulse Buying (Studi Kasus Pada Indomaret di Kota Denpasar). E-Jurnal Ekonomi dan Bisnis Universitas Udayana, 369-394.

Kacen, J. J. (2002). Influence Of Culture On Consumer Implusive Buying Behavior. Journal Of Consumer Psychology, 12 (2), 163-176.

Leba, E. (2015). Pengaruh Atmosfer Gerai Dan Promosi Terhadap Pembelian Impulsif Yang Dimediasi Emosi Positi. Jurnal Ilmu Dan Riset Manajemen, 4(1), 1-17.

Leba, E. (2015). Pengaruh Atmosfer Gerai Dan Promosi Terhadap Pembelian Impulsifyang Dimediasi Emosi Positif. Jurnal Ilmu Dan Riset Manajemen, 4(1), $1-17$.

Levy, M. \&. (2012). Retailing management, (8th ed.). New York: McGraw-Hill/Irwin.

Loudon, D. \&. (1993). Consumer behaviour. Concepts and Applications. New York: Mc Graw-Hill. Impulse Buying Pada Konsumen Ritel. Jurnal Majalah Ekonomi, hal. 192-208.

Ma'ruf, H. (2006). Pemasaran Rite. Jakarta: Gramedia Pustaka Utama.

Ma'ruf, H. (2005). Pemasaran Ritel . Jakarta: Gramedia Pustaka Utama.

Mowen, J. C. (2002). Perilaku konsumen. Alih Bahasa Dwi Kartini Yahya. (Jilid 2, Edisi 5). Jakarta: Erlangga.

Nurcaya, D. A. (2020). Peran Positive Emotion Memediasi Store Atmosphere Terhadap Impulse Buying di Beachwalk Kuta Bali. Fakultas Ekonomi dan Bisnis Universitas Udayana (Unud), Bali, Indonesia, Vol. 9, No.3.
Pattipeilohy, V. R. (2013). The Influence of The Availability of Money and Time, Fashion Involvement, Hedonic Consumtion Tendency and Positive Emotion towards Impulse Buying Behavior in Ambon City. Journal of Business.

Rizky Dwi Rahayu., e. a. (2019). Pengaruh Store Atmosphere Terhadap Pembelian Impulsif Dengan Emosi Positif Sebagai Variabel Mediasi (Studi Pada Centro Departement Store Ambarukmo Plaza Yogyakarta) . Program Studi Manajemen, Fakultas Ekonomi Universitas Muhammadiyah Purworejo. Rook. (1987). The Impulse Buying. The Journal of Consumer Research, Vol.14. No.2.

Rook, D. W. (1995). Normative Influences on Impulsive Buying Behavior. Journal of Consumer Research.

Santoso, S. (2007). Stuctural Equation Modeling Konsep dan Aplikasi dengan AMOS. Jakarta: PT. Elexmedia Komputindo.

Sugiiono. (2012). Metode Penelitian Kuantitatif, Kualitatif, Dan R\&D. Bandung: Alfabeta.

Sugiyono. (2014). Metode Penelitian Pendidikan Pendekatan Kuantitatif, Kualitatif, dan $R \& D$. . Bandung: Alfabeta.

Trihudiyatmanto, M. (2020). Analisa Pengaruh Store Atmosphere dan Promosi Terhadap Impulse Buying Melalui Emotional Response Sebagai Variabel Intervening . Fakultas Ekonomi dan Bisnis Universitas Sains Al-Qur'an Jawa Tengah di Wonosobo, Vol. 3, No. 2.

Utami, W. C. (2017). Manajemen Ritel: Srtategi dan Implementasi Operasional Bisnis Ritel Modern di Indonesia. Edisi 3. Jakarta: Salemba Empat.

Wijayanto, Setyo Hari . (2008). Stuctural Equation Modeling..Yogyakarta: Graha Ilmu. 